\title{
Impact of coronary artery disease on outcomes of severe aortic stenosis treatment with transcatheter aortic valve implantation
}

\author{
Piotr Chodór ${ }^{1}$, Krzysztof Wilczek ${ }^{2}$, tukasz Włoch ${ }^{1}$, Roman Przybylski ${ }^{3}$, Jan Głowacki ${ }^{4}$, Tomasz Kukulski ${ }^{1}$, \\ Tomasz Niklewski ${ }^{3}$, Marian Zembala ${ }^{3}$, Mariusz Gąsior ${ }^{2}$, Zbigniew Kalarus ${ }^{1}$ \\ ${ }^{1}$ Department of Cardiology, Congenital Heart Diseases and Electrotherapy, Silesian Center for Heart Diseases, Medical University of Silesia, \\ Zabrze, Poland \\ ${ }^{2} 3^{\text {rd }}$ Department of Cardiology, Silesian Center for Heart Diseases, Medical University of Silesia, Zabrze, Poland \\ ${ }^{3}$ Department of Cardiac Surgery and Transplantology, Silesian Center for Heart Diseases, Medical University of Silesia, Zabrze, Poland \\ ${ }^{4}$ Diagnostic Department, Department of Radiology, Silesian Center for Heart Diseases, Medical University of Silesia, Zabrze, Poland
}

Adv Interv Cardiol 2019; 15, 2 (56): 167-175

DOI: https://doi.org/10.5114/aic.2019.84394

\begin{abstract}
A bstract
Introduction: The presence of coronary artery disease $(C A D)$ in patients who underwent transcatheter aortic valve implantation (TAVI) may increase in-hospital and long-term mortality.

Aim: To evaluate the impact of CAD in patients who underwent TAVI.

Material and methods: The study group consisted of the first 142 patients treated with TAVI between 26 November 2008 and 31 December 2015. The patients were divided into two groups: group I comprised 103 (72.5\%) patients with CAD, and group II comprised 39 (27.5\%) patients without CAD.

Results: Group I was characterized by a significantly higher risk according to EuroSCORE $-11.2 \pm 2.5$ vs. $9 \pm 2.3$ in group II $(p<0.001)$ and Logistic EuroSCORE $-25.4 \pm 13.4$ vs. $16.3 \pm 8.7$ ( $p<0.001)$. 30-day mortality was $8(7.8 \%)$ vs. $2(5.1 \%)(p=N S)$ and 1 -year mortality was $22(21.4 \%)$ vs. $6(15.4 \%)(p=N S)$ in group I and II respectively. The composite endpoint evaluating the efficacy of TAVI was achieved in $82(79.6 \%)$ vs. $31(79.5 \%)(p=N S)$ in group I and II respectively. The composite endpoint, which involved 30-day observation, occurred in $39(37.86 \%)$ vs. 12 (30.77\%) $(p=N S)$ and the composite endpoint, which involved 1-year evaluation of the clinical efficacy of TAVI, occurred in $48(57.8 \%)$ vs. $13(48.1 \%)(p=N S)$ in patients with and without CAD respectively.

Conclusions: The short- and mid-term outcomes of TAVI patients with CAD, despite higher risk profile, did not differ from the outcomes of treatment in patients without CAD.
\end{abstract}

Key words: percutaneous coronary intervention, coronary artery disease, coronary artery bypass graft, transcatheter aortic valve implantation.

S u m m a ry

We decided to submit the manuscript for your consideration since it concerns a very important clinical problem. This paper may be of significant importance since, to the best of our knowledge it is the first to present data concerning coronary artery disease (CAD) in patients treated with transcatheter aortic valve implantation (TAVI) based on the endpoints suggested by the VARC. The incidence of CAD was found not to affect the in-hospital and 1-year outcomes of treatment of patients suffering from AS using TAVI.

\section{Introduction}

Developed by Alan Cribier in 2002, transcatheter aortic valve implantation (TAVI) has been commonly used to treat severe aortic stenosis (AS) in selected groups of patients [1]. It has been shown that this method improves survival in inoperable patients [2]. The TAVI procedures in high-risk surgical patients were

\section{Corresponding author:}

Piotr Chodór MD, Department of Cardiology, Congenital Heart Diseases and Electrotherapy, Silesian Center for Heart Diseases, Medical University of Silesia, 2 Szpitalna St, 41-800 Zabrze, Poland, phone: +48 32373 36 82, e-mail: chodor_piotr@go2.pl

Received: 9.08.2018, accepted: 10.10.2018. 
found to be equivalent - and, in some studies, even better - in terms of survival compared with surgical aortic valve replacement (SAVR) [3, 4]. There has been a trend to use TAVI in younger patients characterized by lower risk [5, 6]. The 2017 guidelines of the European Society of Cardiology (ESC) expanded the scope of TAVI indications to include intermediate-risk patients [7]. It appears that the long-term effects of treating patients with TAVI may be affected by both valve durability and, most importantly, the progression of coronary artery disease (CAD) if present. The incidence of CAD increases with age; therefore, higher prevalence of CAD in patients who underwent TAVI is understandable. It is estimated that $25-50 \%$ of patients who were treated with SAVR and $40-75 \%$ of patients who received TAVI suffer from CAD [8]. Patients who underwent TAVI include patients after myocardial infarction, coronary artery bypass graft (CABG) and percutaneous coronary intervention $(\mathrm{PCl})$. The $\mathrm{PCl}$ had been performed before TAVI in $11-23 \%$ of the patients as a complex part of treatment of patients suffering from $A S$ and CAD [9-12]. The occurrence of CAD in patients who underwent SAVR doubles the risk of mortality during the perioperative period (from $2.5-3.7 \%$ to $4.5-6.1 \%$ ) [13]. It should be stressed that TAVI procedures are performed in patients with even higher surgical risk. The occurrence of CAD in patients treated with TAVI may increase in-hospital and long-term mortality; however, the data from the literature concerning 1-year observations are ambiguous [10-12, 14-17].

\section{Aim}

The objective of this study was to evaluate the effect of CAD in patients who underwent TAVI on the outcomes of treatment in the in-hospital period and during 1-year observation.

\section{Material and methods}

The TAVI Registry in our hospital is a prospective study, collecting data of patients suffering from severe AS who were referred for TAVI. The aim of the registry is to monitor the outcomes for patients treated with TAVI in terms of safety, efficacy and cost-effectiveness.

Between 26 November 2008 and 31 December 2015, 142 patients were treated with TAVI. This group included patients suffering from severe symptomatic AS with the aortic valve area of $<1 \mathrm{~cm}^{2}$ and/or $<0.6 \mathrm{~cm}^{2} / \mathrm{m}^{2}$, determined through echocardiography, and with a high surgical risk (> 20\% according to the Logistic EuroSCORE and/ or $>10 \%$ according to the Society of Thoracic Surgeons (STS)), or inoperable patients. Other patients with lower surgical risk were also treated with TAVI. They were suffering from comorbidities which were not included in the risk scores, e.g. liver insufficiency, porcelain aorta, conditions after radiation therapy, frailty (Figure 1).

All patients gave informed consent for participation in the study. The TAVI was performed in a Cardiac Catheterization Laboratory or a Hybrid Operating Room. The valve was implanted via transapical, direct aortic, subclavian or transfemoral access. Transapical, direct aortic, subcla-

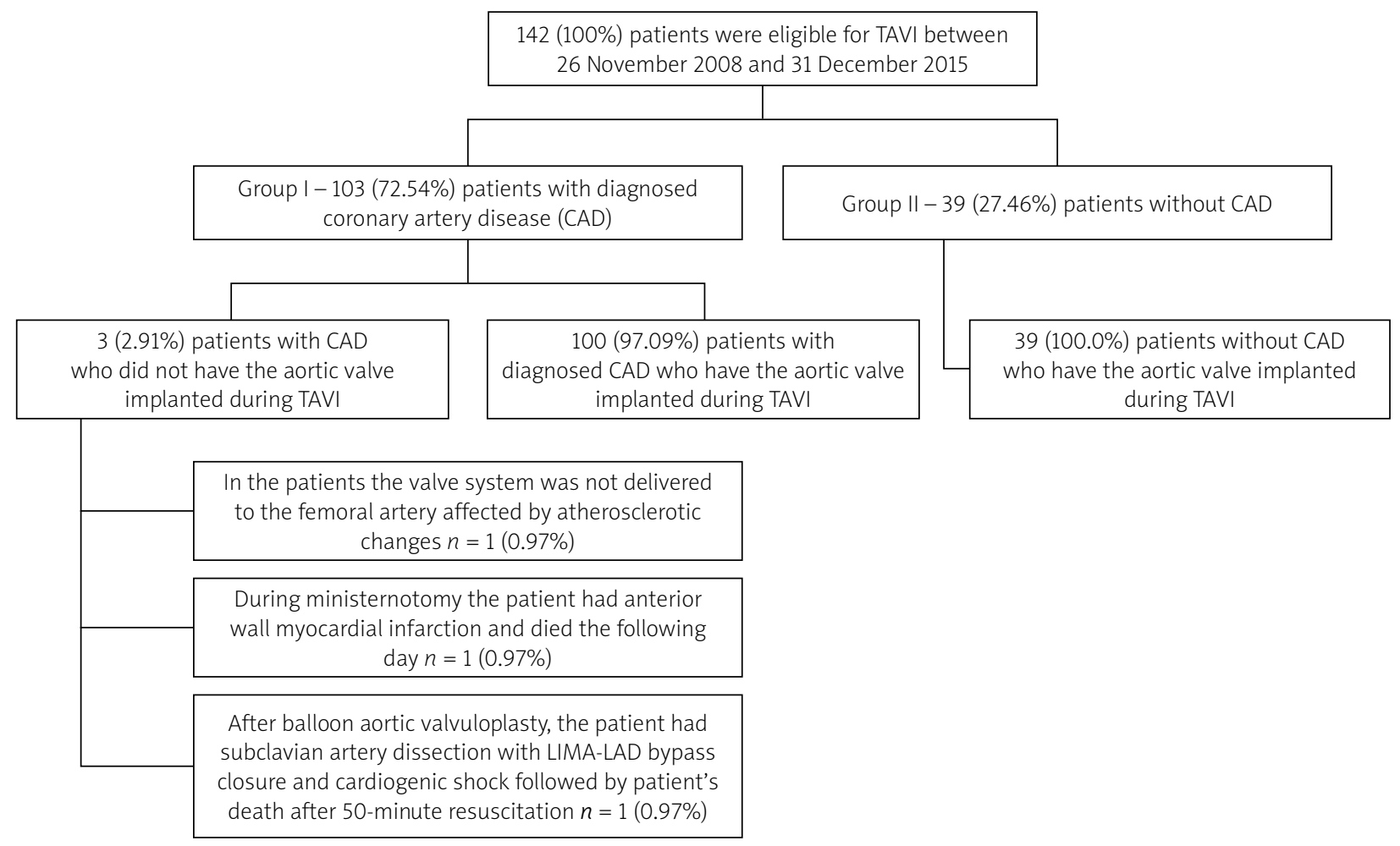

Figure 1. General characteristics of patients eligible for transcatheter aortic valve implantation (TAVI) 
vian and certain transfemoral procedures were performed under general anesthesia with surgical exposure of the access site. Other transfemoral access procedures were carried out percutaneously under local anesthesia with sedation and using vascular closure devices. 109 (77.9\%) CoreValve and Evolut R aortic valves (Medtronic, Minneapolis, MN, USA), sizes 26, 29, 31 and 34, were implanted, and 31 (22.1\%) Edwards SAPIEN and Edwards SAPIEN XT (Edwards Lifesciences, Irvine, California, USA) aortic valves, sizes 23, 26 and 29, were implanted. The procedures were performed as a routine TAVI as described elsewhere [1820]. According to the decision of the Heart Team, some patients had received balloon aortic valvuloplasty (BAV) as a bridge to TAVI, and some had their planned $\mathrm{PCl}$ performed as a complex treatment of patients with CAD and AS. Patients with stenosis of the main branches of coronary arteries at $>70 \%$ of the diameter were selected by the Heart Team as eligible for these procedures [7, 21].

The patients were divided into two groups. Group I comprised 103 (72.5\%) patients with diagnosed CAD.

Table I. Clinical characteristics of patients and procedural data

\begin{tabular}{|c|c|c|c|c|}
\hline Parameter & $\begin{array}{l}\text { Study group } \\
(n=142)\end{array}$ & $\begin{array}{c}\text { Group I } \\
(n=103)\end{array}$ & $\begin{array}{l}\text { Group II } \\
(n=39)\end{array}$ & $P$-value \\
\hline Age [years] & $76.8 \pm 8.4$ & $77.5 \pm 7.8$ & $74.8 \pm 9.7$ & NS \\
\hline Male, $n(\%)$ & $71(50.0)$ & $53(51.5)$ & $18(46.2)$ & NS \\
\hline Body mass index $\left[\mathrm{kg} / \mathrm{m}^{2}\right]$ & $28.2 \pm 4.9$ & $28.1 \pm 4.1$ & $28.2 \pm 6.5$ & NS \\
\hline Body surface area [m²] & $1.8 \pm 0.2$ & $1.8 \pm 0.2$ & $1.8 \pm 0.2$ & NS \\
\hline EuroSCORE standard & $10.7 \pm 2.7$ & $11.3 \pm 2.6$ & $9.0 \pm 2.3$ & $<0.001$ \\
\hline Logistic EuroSCORE (\%) & $23.2 \pm 13.5$ & $25.7 \pm 14.0$ & $16.1 \pm 8.7$ & $<0.001$ \\
\hline STS score (\%) & $5.9 \pm 3.8$ & $5.9 \pm 3.8$ & $5.6 \pm 3.7$ & NS \\
\hline Previous myocardial infarction & $51(35.9 \%)$ & $51(49.5 \%)$ & $0(0 \%)$ & $<0.001$ \\
\hline Previous PCI & $83(58.5 \%)$ & $83(80.6 \%)$ & $0(0 \%)$ & $<0.001$ \\
\hline Previous CABG & $42(29.6 \%)$ & $42(40.8 \%)$ & $0(0 \%)$ & $<0.001$ \\
\hline Hypertension & $102(71.8 \%)$ & $80(77.7 \%)$ & $22(56.4 \%)$ & 0.0118 \\
\hline Diabetes & $62(43.7 \%)$ & $47(45.6 \%)$ & 15 (38.5\%) & NS \\
\hline Smoking & $50(35.2 \%)$ & $41(39.8 \%)$ & $9(23.1 \%)$ & 0.0629 \\
\hline Chronic obstructive pulmonary disease & $37(26.1 \%)$ & $25(24.3 \%)$ & $12(30.8 \%)$ & NS \\
\hline Dialysis patients & $3(2.1 \%)$ & $3(2.9 \%)$ & $0(0 \%)$ & NS \\
\hline Patients with pacemaker implanted & $27(19.0 \%)$ & $24(23.3 \%)$ & $3(7.7 \%)$ & 0.0345 \\
\hline NYHA III & $64(45.1 \%)$ & $49(47.6 \%)$ & $15(38.5 \%)$ & NS \\
\hline NYHA IV & $7(4.9 \%)$ & $3(2.9 \%)$ & $4(10.3 \%)$ & 0.0691 \\
\hline NT-proBNP [pg/ml] & $3828.3 \pm 5322.3$ & $3609.8 \pm 4722.2$ & $4476.9 \pm 6851.1$ & NS \\
\hline Creatinine $[\mu \mathrm{mol} / /]$ & $105.2 \pm 47.0$ & $109.3 \pm 51.2$ & $93.7 \pm 30.4$ & NS \\
\hline Hemoglobin $[\mathrm{mmol} / \mathrm{l}]$ & $7.4 \pm 1.3$ & $7.4 \pm 1.2$ & $7.2 \pm 1.5$ & NS \\
\hline Heart rate & $75.2 \pm 14.4$ & $75.7 \pm 13.5$ & $73.7 \pm 17.0$ & NS \\
\hline QRS duration [ms] & $113.8 \pm 29.4$ & $114.0 \pm 28.9$ & $113.3 \pm 31.3$ & NS \\
\hline Procedure duration [min] & $198.1 \pm 54.2$ & $198.4 \pm 58.2$ & $197.3 \pm 41.1$ & NS \\
\hline Absorbed dose [mGy] & $2382.1 \pm 1550.7$ & $2431.2 \pm 1599.2$ & $2240.9 \pm 1415.3$ & NS \\
\hline Volume of used contrast medium [ml] & $204.1 \pm 82.5$ & $199.3 \pm 76.9$ & $217.0 \pm 95.9$ & NS \\
\hline Fluoroscopy time [min] & $31.5 \pm 16.1$ & $32.7 \pm 17.8$ & $28.1 \pm 9.1$ & NS \\
\hline Moderate/severe PVL & $13(9.2 \%)$ & $11(10.7 \%)$ & $2(5.1 \%)$ & NS \\
\hline
\end{tabular}

CABG - coronary artery bypass grafting, NT-proBNP - N-terminal natriuretic propeptide type B, NYHA - New York Heart Association, PCI - percutaneous coronary intervention, STS - Society of Thoracic Surgeons, PVL - paravalvular leak evaluated angiographically immediately after implantation. 
This group included patients after PCI, CABG, with a history of myocardial infarction, and patients with stenosis of at least one coronary artery at $\geq 50 \%$ of its diameter. The remaining 39 (27.5\%) patients constituted group II non-CAD (Table I).

VARC-2 criteria were applied to assess the outcomes [22].

The patients were evaluated during hospitalization as well as 30 days, 6 months and 12 months after the procedure at the outpatient clinic.

\section{Statistical analysis}

The numerical data obtained during the study were expressed as mean and standard deviation. The Kolmogorov-Smirnov test was used to evaluate the similarity of distributions to the normal distribution. If the distribution of two variables in a pair was similar to the normal distribution, Student's $t$-test was used for independent and dependent variables. Differences between qualitative parameters were assessed based on the $\chi^{2}$ test with Yates's correction, and Fisher's test was applied in the case of small groups. Cumulative event rates were estimated by means of the Kaplan-Meier method. The logrank test was applied to compare the survival curves. The level of statistical significance was $p<0.05$. Statistica 10 software was used to perform the calculations.

\section{Results}

The study group was selected out of 253 patients qualified for TAVI/AVR by the Heart Team. One hundred and forty-two patients eligible for TAVI were selected for the analysis.

Patients were divided according to the presence of CAD. Group I comprised 103 (72.5\%) patients with diagnosed CAD. The remaining 39 (27.5\%) patients constituted group II - without CAD.

Twenty-five $(24.3 \%)$ patients from group I underwent $\mathrm{PCl}$ before TAVI as a complex treatment of AS and CAD. The $\mathrm{PCl}$ was performed as a staged procedure in 22 (21.4\%) patients - PCI first, followed by TAVI after several days/weeks. $\mathrm{PCl}$ and TAVI were performed in one stage in $3(2.9 \%)$ patients. TAVI was performed in 20 (14.1\%) patients via transapical access, in $8(5.6 \%)$ patients via direct aortic access, in 25 (17.6\%) patients via subclavian access, and in $89(62.7 \%)$ patients via transfemoral access. 105 (75.5\%) CoreValve aortic valves, 3 (2.2\%) Evolut $\mathrm{R}$ aortic valves, 23 (16.5\%) Edwards Sapien aortic valves, and 8 (5.8\%) Edwards Sapien XT aortic valves were implanted.

Table I shows the characteristics of the study groups. The patients with CAD were characterized by a significantly higher surgical risk according to the Standard $(11.3 \pm 2.6$ vs. $9.0 \pm 2.3, p<0.001)$ and the Logistic EuroSCORE $(25.7 \pm 14.0 \%$ vs. $16.1 \pm 8.7 \%, p<0.001)$, higher incidence of hypertension $(77.7 \%$ vs. $56.4 \%, p=0.0118)$ and a higher rate of pacemaker implantation prior to the procedure $(23.3 \%$ vs. $7.7 \%, p=0.0345)$.

The echocardiographic data before and after TAVI are presented in Table II.

Thirty-day mortality was 8 (7.8\%) in group I and 2 (5.1\%) in group II ( $p=N S)$. One-year mortality was $22(21.4 \%)$ and $6(15.4 \%)$ in group I and II, respectively ( $p=N S$ ).

The data were analyzed according to the VARC- 2 criteria, which comprised device success, 30-day TAVI safety and clinical efficacy of TAVI within 1 year [22].

The composite endpoint evaluating the efficacy of the aortic valve implantation was achieved in 82 (79.6\%) CAD patients and in 31 (79.5\%) non-CAD patients ( $p=$ NS) (Table III).

The secondary composite endpoint, which comprised early safety during 30-day observation, occurred in 39 (37.86\%) patients of the CAD group and in 12 (30.77\%) patients of the non-CAD group ( $p=$ NS) (Table III).

The tertiary composite endpoint occurred in 48 (57.8\%) patients from group I, and in 13 (48.1\%) patients from group II ( $p=\mathrm{NS}$ ) (Table III).

The survival curves are shown in Figure 2. There were no differences between the patients with and without CAD or between separate age groups in terms of survival.

Echocardiographic results are shown in Figure 3. Both groups experienced a significant reduction of the mean aortic valve gradient and an increase in the aortic valve area and indexed area. These changes were maintained in the case of 30-day and 1-year observations. There were no significant differences in this regard between group I and II, except for a significantly lower left ventricular ejection fraction during 1-year observation in group I (Table II).

\section{Discussion}

This paper presents data concerning CAD in patients treated with TAVI based on the endpoints suggested by the VARC. We found that the occurrence of CAD did not affect the in-hospital and 1-year outcomes of treatment of patients suffering from AS treated with TAVI. In the whole study group the prevalence of CAD was $72.5 \%$, which is one of the highest to be found in the literature [4]. According to the literature, CAD was diagnosed in $25-50 \%$ of patients with severe AS and in $40-75 \%$ of patients undergoing TAVI depending on the criteria adopted for CAD diagnosis [8]. In this paper, we applied the criterion of stenosis of over $50 \%$ in major pericardial arteries in coronary angiograms performed before TAVI. Although it may seem quite liberal, this study involved a considerable number of patients who had a history of myocardial infarction - 51 (35.9\%), CABG - 42 (29.6\%) or $\mathrm{PCl}-83$ (58.5\%). Similar criteria were adopted by Masson et al. and Abdel-Wahab et al. [10, 23]. Patients with CAD are characterized by a significantly higher surgical risk according to the Standard and Logistic EuroSCORE or the STS scores. This is caused by a higher incidence of 
factors associated with atherosclerosis that increase the risk calculated with these scores. The above-mentioned factors include extracardiac arteriopathy, previous cardiac surgery, myocardial infarction up to 90 days before the procedure, and reduced ejection fraction.
The outcomes for TAVI patients with and without CAD are varied in the literature. In a study from 2010, performed on a group of 171 patients with and without CAD, Dewey et al. demonstrated a higher risk of 30-day (13.1\% and $1.2 \%, p=0.002$, respectively) and 1-year mortality

Table II. Echocardiographic data before TAVI, echocardiographic data during 30-day observation after TAVI and 1-year observation after TAVI

\begin{tabular}{|c|c|c|c|c|}
\hline Echocardiographic data before TAVI & $\begin{array}{l}\text { Study group } \\
(n=142)\end{array}$ & $\begin{array}{c}\text { Group I } \\
(n=103)\end{array}$ & $\begin{array}{l}\text { Group II } \\
(n=39)\end{array}$ & $P$-value \\
\hline LVEF (\%) & $45.2 \pm 12.3$ & $43.8 \pm 12.4$ & $49.5 \pm 11.0$ & NS \\
\hline Aortic valve area $\left[\mathrm{cm}^{2}\right]$ & $0.6 \pm 0.2$ & $0.6 \pm 0.2$ & $0.6 \pm 0.3$ & NS \\
\hline Aortic valve area index $\left[\mathrm{cm}^{2} / \mathrm{m}^{2}\right]$ & $0.3 \pm 0.1$ & $0.3 \pm 0.1$ & $0.3 \pm 0.2$ & NS \\
\hline Mean LV/Ao gradient [mm Hg] & $51.8 \pm 18.9$ & $51.4 \pm 19.3$ & $53.0 \pm 17.7$ & NS \\
\hline Peak velocity through aortic valve $[\mathrm{m} / \mathrm{s}]$ & $4.3 \pm 0.7$ & $4.3 \pm 0.7$ & $4.3 \pm 0.8$ & NS \\
\hline Pulmonary artery systolic pressure [mm Hg] & $49.8 \pm 14.6$ & $48.7 \pm 12.2$ & $52.5 \pm 19.6$ & NS \\
\hline Mitral regurgitation: moderate/severe & $30(21.1 \%)$ & $26(25.2 \%)$ & $4(10.3 \%)$ & 0.0521 \\
\hline Tricuspid regurgitation: moderate/severe & $22(15.5 \%)$ & $16(15.5 \%)$ & $6(15.4 \%)$ & NS \\
\hline Annulus diameter in TTE [mm] & $23.0 \pm 2.4$ & $23.1 \pm 2.3$ & $22.8 \pm 2.5$ & NS \\
\hline Annulus diameter in TEE [mm] & $23.3 \pm 2.6$ & $23.2 \pm 2.5$ & $23.5 \pm 3.0$ & NS \\
\hline 30-day observation after TAVI & $\begin{array}{l}\text { Study group } \\
(n=132)\end{array}$ & $\begin{array}{c}\text { Group I } \\
\left(n=95^{*}\right)\end{array}$ & $\begin{array}{c}\text { Group II } \\
\left(n=37^{\star *}\right)\end{array}$ & $P$-value \\
\hline LVEF (\%) & $49.0 \pm 10.2$ & $48.6 \pm 10.4$ & $50.0 \pm 9.5$ & NS \\
\hline Aortic valve area $\left[\mathrm{cm}^{2}\right]$ & $1.7 \pm 0.4$ & $1.7 \pm 0.5$ & $1.5 \pm 0.3$ & NS \\
\hline Aortic valve area index $\left[\mathrm{cm}^{2} / \mathrm{m}^{2}\right]$ & $0.9 \pm 0.3$ & $0.9 \pm 0.3$ & $0.8 \pm 0.2$ & NS \\
\hline Mean LV/Ao gradient [mm Hg] & $10.4 \pm 4.8$ & $10.3 \pm 5.1$ & $10.7 \pm 4.1$ & NS \\
\hline Peak velocity through aortic valve $[\mathrm{m} / \mathrm{s}]$ & $2.2 \pm 1.8$ & $2.3 \pm 2.0$ & $1.9 \pm 0.8$ & NS \\
\hline Pulmonary artery systolic pressure [mm Hg] & $42.6 \pm 11.0$ & $41.4 \pm 10.5$ & $46.0 \pm 12.2$ & NS \\
\hline Mitral regurgitation: moderate/severe & $11(8.3 \%)$ & $6(6.3 \%)$ & $5(13.5 \%)$ & NS \\
\hline Tricuspid regurgitation: moderate/severe & $18(13.6 \%)$ & $12(12.6 \%)$ & $6(16.2 \%)$ & NS \\
\hline \multicolumn{5}{|c|}{ *All-cause mortality - 8 (7.8\%), ${ }^{* * A l l-c a u s e ~ m o r t a l i t y ~-~} 2$ (5.1\%) } \\
\hline One-year observation after TAVI & $\begin{array}{l}\text { Study group } \\
(n=114)\end{array}$ & $\begin{array}{c}\text { Group I } \\
\left(n=81^{\star * *}\right)\end{array}$ & $\begin{array}{c}\text { Group II } \\
\left(n=26^{\star * \star *}\right)\end{array}$ & $P$-value \\
\hline LVEF (\%) & $49.6 \pm 11.7$ & $47.9 \pm 12.1$ & $54.3 \pm 9.4$ & 0.0153 \\
\hline Aortic valve area $\left[\mathrm{cm}^{2}\right]$ & $1.7 \pm 0.5$ & $1.7 \pm 0.5$ & $1.4 \pm 0.3$ & NS \\
\hline Aortic valve area index $\left[\mathrm{cm}^{2} / \mathrm{m}^{2}\right]$ & $0.9 \pm 0.2$ & $0.9 \pm 0.3$ & $0.8 \pm 0.2$ & NS \\
\hline Mean LV/Ao gradient [mm Hg] & $9.5 \pm 4.8$ & $9.1 \pm 4.6$ & $10.4 \pm 5.3$ & NS \\
\hline Peak velocity through aortic valve $[\mathrm{m} / \mathrm{s}]$ & $2.0 \pm 0.5$ & $2.0 \pm 0.5$ & $2.0 \pm 0.6$ & NS \\
\hline Pulmonary artery systolic pressure [mm Hg] & $44.0 \pm 11.5$ & $43.4 \pm 11.7$ & $45.9 \pm 11.2$ & NS \\
\hline Mitral regurgitation: moderate/severe & $10(8.8 \%)$ & $7(8.6 \%)$ & $3(11.5 \%)$ & NS \\
\hline Tricuspid regurgitation: moderate/severe & $14(12.3 \%)$ & $11(13.6 \%)$ & $3(11.5 \%)$ & NS \\
\hline
\end{tabular}


Table III. Composite endpoint evaluating the efficacy of aortic valve implantation; composite endpoint - 30day observation; composite endpoint - 1-year evaluation of the clinical efficacy of transcatheter aortic valve implantation

\begin{tabular}{|c|c|c|c|}
\hline Parameter & $\begin{array}{c}\text { Group I } \\
(n=103)\end{array}$ & $\begin{array}{l}\text { Group II } \\
(n=39) \\
\end{array}$ & $P$-value \\
\hline \multicolumn{4}{|l|}{ Device success: } \\
\hline Absence of procedural mortality & $102(99 \%)$ & $38(97.4 \%)$ & NS \\
\hline $\begin{array}{l}\text { Correct positioning of a single prosthetic aortic valve into the proper } \\
\text { anatomical location }\end{array}$ & $99(96.1 \%)$ & $38(97.4 \%)$ & NS \\
\hline $\begin{array}{l}\text { Intended performance of the prosthetic aortic valve (no prosthesis - } \\
\text { patient severe mismatch and mean aortic valve gradient }<20 \mathrm{~mm} \mathrm{Hg} \\
\text { or peak velocity }<3 \mathrm{~m} / \mathrm{s} \text {, and no moderate or severe prosthetic valve } \\
\text { regurgitation) }\end{array}$ & $87(84.5 \%)$ & $31(79.5 \%)$ & NS \\
\hline Composite endpoints (expressed as number of patients) & $21(20.4 \%)$ & $8(20.5 \%)$ & NS \\
\hline \multicolumn{4}{|l|}{ Early safety (at 30 days): } \\
\hline All-cause mortality & $8(7.8 \%)$ & $2(5.1 \%)$ & NS \\
\hline Stroke (disabling and non-disabling) & $3(2.9 \%)$ & $1(2.6 \%)$ & NS \\
\hline Life-threatening hemorrhaging & $26(25.2 \%)$ & $10(25.6 \%)$ & NS \\
\hline $\begin{array}{l}\text { Acute kidney injury - stage } 2 \text { or } 3 \text { (including renal replacement } \\
\text { therapy) }\end{array}$ & $8(7.8 \%)$ & $2(5.1 \%)$ & NS \\
\hline Coronary artery obstruction requiring intervention & $0(0 \%)$ & $0(0 \%)$ & NS \\
\hline Major vascular complication & $12(11.7 \%)$ & $2(5.1 \%)$ & NS \\
\hline Valve-related dysfunction requiring another procedure (BAV, TAVI or SAVR) & $0(0 \%)$ & $0(0 \%)$ & NS \\
\hline Composite endpoints (expressed as number of patients) & $39(37.86 \%)$ & $12(30.77 \%)$ & NS \\
\hline \multicolumn{4}{|l|}{ Clinical efficacy (1-year evaluation): } \\
\hline All-cause mortality & $22(21.4 \%)$ & $6(15.4 \%)$ & NS \\
\hline Stroke (disabling and non-disabling) & $3(2.9 \%)$ & $2(5.1 \%)$ & NS \\
\hline $\begin{array}{l}\text { Requiring hospitalizations for valve-related symptoms or worsening } \\
\text { congestive heart failure }\end{array}$ & $14(16.86 \%)^{*}$ & $4(15.4 \%)^{\star \star}$ & NS \\
\hline NYHA class III or IV & $14(16.86 \%)^{*}$ & $2(7.7 \%)^{\star *}$ & NS \\
\hline $\begin{array}{l}\text { Valve-related dysfunction (mean aortic valve gradient } \geq 20 \mathrm{~mm} \mathrm{Hg} \text {, } \\
\text { EOA } \leq 0.9-1.1 \mathrm{~cm}^{2} \text { and/or DVI } 0.35 \mathrm{~m} / \mathrm{s} \text {, and/or moderate or severe } \\
\text { prosthetic valve regurgitation) }\end{array}$ & $14(17.28 \%)^{\star * *}$ & $5(19.2 \%)^{\star \star}$ & NS \\
\hline Composite endpoints (expressed as number of patients) & $49(47.6 \%)$ & $14(35.9 \%)$ & NS \\
\hline
\end{tabular}

${ }^{*} n=83$ patients, ${ }^{* *} n=26$ patients, ${ }^{* * *} n=81$ patients. BAV - balloon aortic valvuloplasty, SAVR - surgical aortic valve replacement, TAVI - transcatheter aortic valve implantation, DVI - Doppler velocity index, EOA - effective orifice area, NYHA - New York Heart Association.

(35.7\% and $18.4 \%, p=0.01$, respectively) among patients with CABG and PCI [14]. In a group of 164 TAVI patients, Khawaja et al. revealed a similarly higher mortality in CAD patients (CAD defined as over-70\% stenosis of coronary arteries, or over-50\% in the case of the left main coronary artery). Thirty-day mortality was $16.7 \%$ and $3.8 \%$ respectively, and mortality after 1 year was $31.5 \%$ vs. $14.4 \%$ [17]. In addition, Huczek et al., based on the PoITAVI registry, demonstrated a higher risk of death in patients with CAD treated with TAVI in comparison with patients without CAD in mid-term observation $(8.7 \% \mathrm{vs.}$ $5.1 \%$, log-rank $p=0.039$ ) [24]. However, the outcomes of numerous other studies did not show the impact of
CAD on the prognosis for patients who underwent TAVI $[8,10-12,15,16]$.

Several issues must be taken into account in order to discuss these discrepancies. First of all, this may result from the inadequacy of risk scores used to evaluate patients admitted for cardiac surgery, but not for TAVI. The TAVI is significantly less risky for patients, especially in the case of percutaneous TAVI under deep sedation and when the safest access route may be applied. It seems necessary to develop dedicated risk calculators exclusively for TAVI. Furthermore, the issue concerning the risk of mortality associated with CAD in patients after TAVI should be addressed. Based on the studies men- 
A

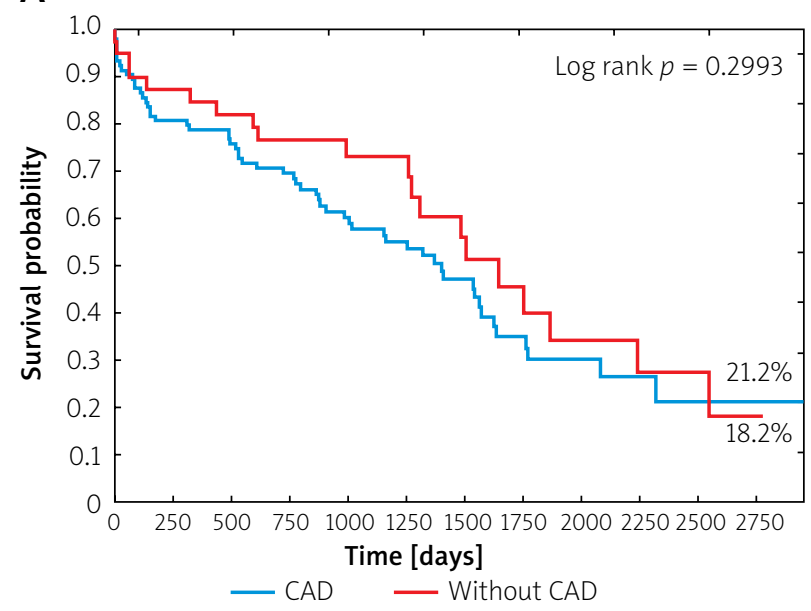

C

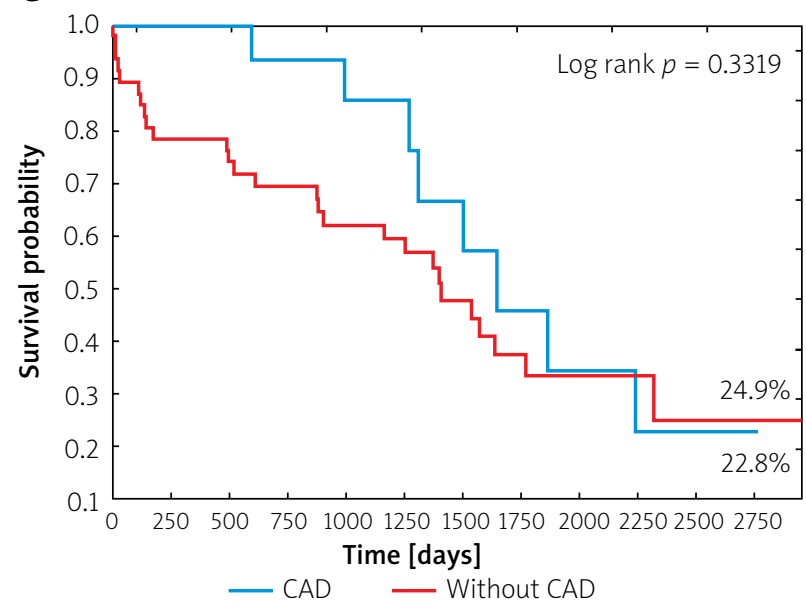

B

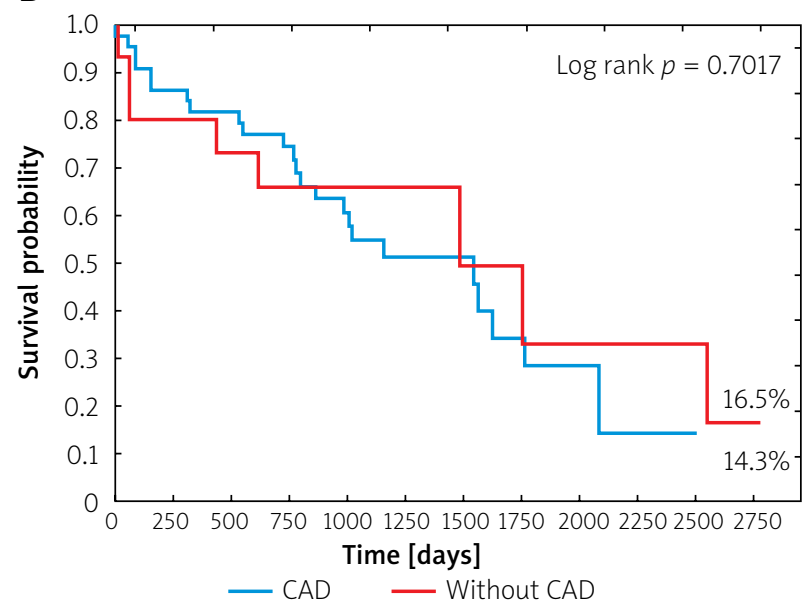

D

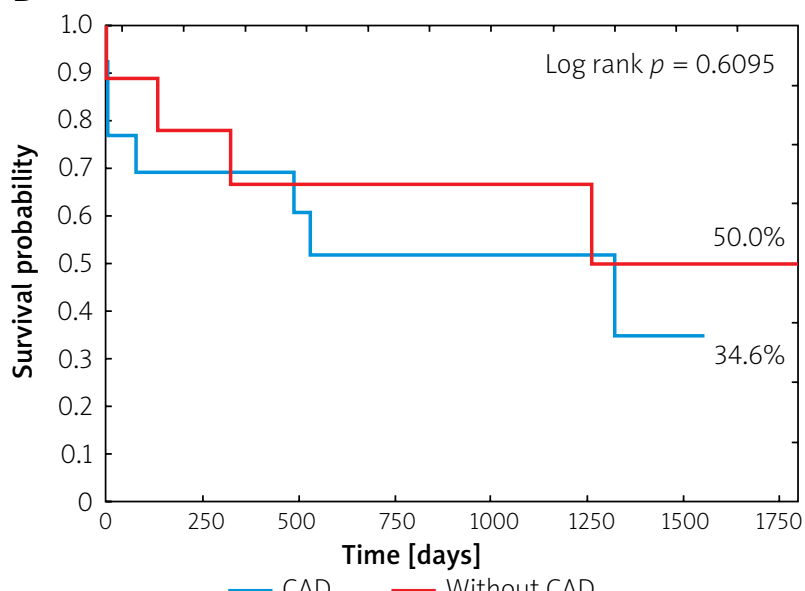

Figure 2. A - Survival curves of patients with and without CAD; B - survival curves of patients with CAD and without it aged $\geq 80 ; C$ - survival curves of patients with CAD and without it aged $\geq 70$ but $<80 ; D$ - survival curves of patients with CAD and without it aged $<70$

tioned below, CAD as a risk factor itself has a limited impact on survival in short- and mid-term observations as compared to other factors presented in TAVI patients. According to the GARY registry, 1-year mortality among patients who underwent TAVI is $19.9 \%$ [25]. This is an outcome comparable to the outcome achieved by us. The GARY registry indicated that among the pre-operative factors, 1-year mortality is affected by the following: higher risk according to the Logistic EuroSCORE, previous mitral insufficiency $\geq$ grade 2 , low-gradient AS, previous decompensation, previous myocardial infarction, renal failure, NYHA class IV, female gender. Among procedural and postprocedural factors, the following were associated with a poorer prognosis: intraprocedural conversion to surgery, peri-interventional stroke, residual aortic insufficiency $\geq$ grade 2 , post-intervention myocardial infarction and pulmonary embolism. A registry from the UK indicates that 1-year mortality between 2007 and 2009 was $21.4 \%$, whereas 3 -year mortality was $38.8 \%$. The independent risk factors of mortality within 3 years includ-

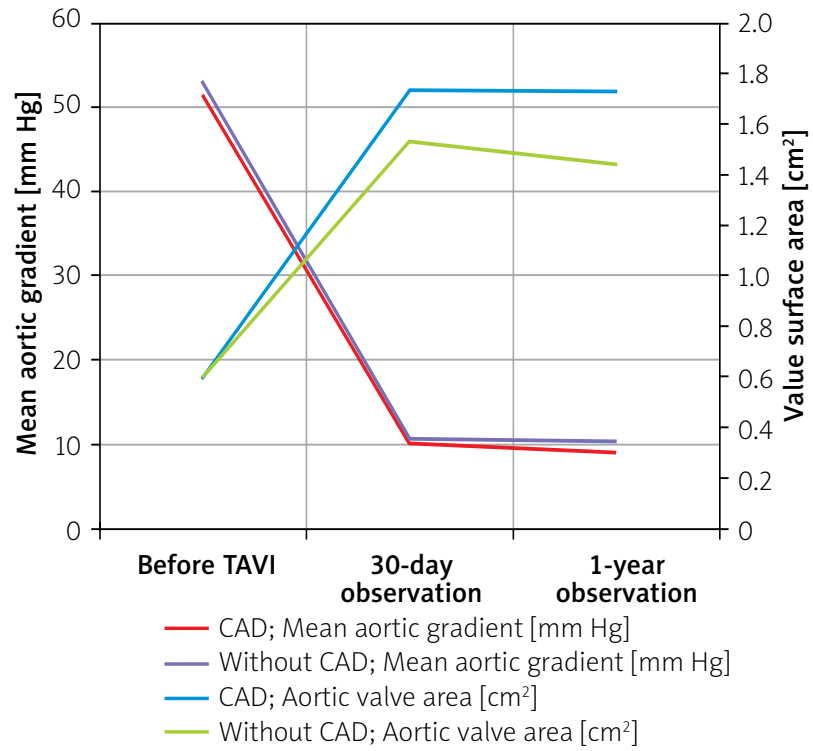

Figure 3. Echocardiographic parameters in group I and II during the 30-day and 1-year follow-up 
ed renal insufficiency, a Logistic EuroSCORE of $\geq 18.5 \%$, chronic lung disease and low ejection fraction. Within 5 years, the mortality risk factors additionally included coronary artery disease and age [26].

On the basis of these registries, it may be concluded that CAD is a mortality risk factor only after 5 years in the UK registry, while in the GARY registry CAD is expressed in the form of such factors as previous or post-intervention myocardial infarction.

Such a limited impact of CAD on the outcomes of $T A V I$, not only in the registries but also in the above-mentioned clinical studies, may result from pre-TAVI revascularization by means of either previous CABG or PCl. Both $\mathrm{PCl}$ and CABG performed prior to TAVI may cause the proportion of patients with full revascularization before TAVI to be high, and therefore their prognosis to be better [27]. Likewise, patients suffering only from stable CAD instead of AS exhibit good prognoses after successful revascularization. Serruys et al. argue that in patients with three-vessel coronary artery disease with or without left main involvement, the incidence of repeat revascularization or death within 1-year observation is $13.5 \%$ and $4.4 \%$ in the case of $\mathrm{PCl}$, and $5.9 \%$ and $3.5 \%$ respectively in the case of CABG. The average age of the patients and the risk according to EuroSCORE were $65.2 \pm 9.7$ years and $3.8 \pm 2.6 \%$ in the case of $\mathrm{PCl}$ and $65.0 \pm 9.8$ years and $3.8 \pm 2.7 \%$ in the case of CABG, respectively [28].

On the other hand, the authors of the SYNTAX study found that the incidence of repeat revascularization and death within 5 years was $25.9 \%$ and $13.9 \%$ in the case of $\mathrm{PCl}$, and $13.7 \%$ and $11.4 \%$ in the case of CABG, respectively [29]. Based on this study, it can be expected that the necessity of additional revascularization of coronary arteries within 5 years would be 11.7-25.9\%.

The mortality rate of the SYNTAX study patients with complete revascularization is low even 5 years after the index procedure as compared to the high mortality rate after TAVI in the UK registry [26]. In addition, on the basis of their 3.5-year observation, Rodes-Cabau et al. [30] argued that half of the deaths of the patients who had undergone TAVI were due to extracardiac causes, whereas myocardial infarction, as a cardiac cause, resulted in a mortality rate of $3.9 \%$.

It is likely that 3-6 months of post-procedural treatment with a dual antiplatelet therapy (DAPT) in patients after TAVI may usually contribute to lower mortality in those who also suffer from CAD. Patients who were treated with $\mathrm{PCI}$ during or before TAVI receive a prolonged (up to 12 months) DAPT [31].

On the basis of the presented outcomes, CAD cannot be considered as a factor that worsens the short-term and mid-term prognosis for patients treated with TAVI as opposed to CAD patients undergoing SAVR [32]. Our population was a high-risk surgery group according to the risk scores, and the presented results pertain to patients of this particular risk profile. It is likely that after switching to intermediate- and low-risk patients admitted for $T A V I$, the presence of CAD may affect the prognosis in a different way. This possibility should be investigated further.

\section{Limitations of the study}

The study is a single-center trial and involves a relatively small number of patients.

\section{Conclusions}

Patients with CAD are characterized by a significantly higher risk of surgical treatment, higher incidence of hypertension and likelihood of a pacemaker implanted prior to the procedure during selection and qualification for TAVI. The short- and mid-term outcomes for high-risk TAVI patients with and without CAD are comparable.

\section{Conflict of interest}

The authors declare no conflict of interest.

\section{References}

1. Cribier A, Eltchaninoff $\mathrm{H}$, Bash A, et al. Percutaneous transcatheter implantation of an aortic valve prosthesis for calcific aortic stenosis: first human case description. Circulation 2002; 106: 3006-8.

2. Leon MB, Smith CR, Mack $M$, et al. Transcatheter aortic-valve implantation for aortic stenosis in patients who cannot undergo surgery. N Engl J Med 2010; 363: 1597-607.

3. Stortecky S, Brinks H, Wenaweser P, et al. Transcatheter aortic valve implantation or surgical aortic valve replacements redo procedure after prior coronary artery bypass grafting. Ann Thorac Surg 2011; 92: 1324-30.

4. Smith CR, Leon MB, Mack MJ, et al.; the PARTNER Trial Investigators. Transcatheter versus surgical aortic-valve replacement in high-risk patients. N Engl J Med 2011; 364: 2187-98.

5. Reardon MJ, Van Mieghem NM, Popma JJ, et al.; the SURTAVI Investigators. Surgical or transcatheter aortic-valve replacement in intermediate-risk patients. N Engl J Med 2017; 376: 1321-31.

6. Arora S, Ramm CJ, Misenheimer JA, et al. TAVR in Intermediate-risk patients: a review of the PARTNER 2 trial and its future implications. J Heart Valve Dis 2016; 25: 653-6.

7. Baumgartner H, Falk V, Bax JJ, et al. 2017 ESC/EACTS Guidelines for the management of valvular heart disease. Eur Heart J 2017; 38: 2739-91.

8. Goel SS, Ige M, Tuzcu EM, et al. Severe aortic stenosis and coronary artery disease - implications for management in the transcatheter aortic valve replacement era: a comprehensive review. J Am Coll Cardiol 2013; 62: 1-10.

9. Moat NE, Ludman P, de Belder MA, et al. Long-term outcomes after transcatheter aortic valve implantation in high-risk patients with severe aortic stenosis: the U.K. TAVI (United Kingdom Transcatheter Aortic Valve Implantation) Registry. J Am Coll Cardiol 2011; 58: 2130-8.

10. Masson JB, Lee M, Boone RH, et al. Impact of coronary artery disease on outcomes after transcatheter aortic valve implantation. Catheter Cardiovasc Interv 2010; 76: 165-73. 
11. Gautier M, Pepin M, Himbert D, et al. Impact of coronary artery disease on indications for transcatheter aortic valve implantation and on procedural outcomes. Eurolntervention 2011; 7 : 549-55.

12. Wenaweser P, Pilgrim T, Guerios E, et al. Impact of coronary artery disease and percutaneous coronary intervention on outcomes in patients with severe aortic stenosis undergoing transcatheter aortic valve implantation. Eurolntervention 2011; 7: 541-8.

13. Hamm CW, Möllmann H, Holzhey D, et al.; GARY-Executive Board. The German Aortic Valve Registry (GARY): in-hospital outcome. Eur Heart J 2014; 35: 1588-98.

14. Dewey MT, Brown DL, Herbert MA, et al. Effect of concomitant coronary artery disease on procedural and late outcomes of transcatheter aortic valve implantation. Ann Thorac Surg 2010; 89: 758-67.

15. Ussia GP, Barbanti M, Colombo A, et al. Impact of coronary artery disease in elderly patients undergoing transcatheter aortic valve implantation: insight from the Italian CoreValve Registry. Int J Cardiol 2013; 167: 943-50.

16. Wendler O, Schroefel H, Rastan A, et al. Does previous coronary bypass surgery increase the risk for patients undergoing TAVI? Eurolntervention 2011; 7 (Suppl M): 430.

17. Khawaja MZ, Asrress KN, Haran H, et al. The effects of pre-existing significant coronary artery disease defined by QCA analysis upon outcome after transcatheter aortic valve implantation using the Edwards bioprosthesis. J Am Coll Cardiol 2011; 58 (Suppl): B201-2.

18. Chodór P, Wilczek K, Przybylski R, et al. Immediate and 6-month outcomes of transapical and transfemoral Edwards-Sapien prosthesis implantation in patients with aortic stenosis. Kardiol Pol 2010; 68: 1124-31.

19. Wilczek K, Chodór P, Walas R, et al. 'Valve-in-valve' - first Polish experience in transcatheter treatment of patient with high-risk of redo surgery for degenerative disease of aortic bioprosthesis, using transaxillary access. Kardiol Pol 2010; 68: 980-4.

20. Wilczek K, Chodór P, Laborde JC, et al. Percutaneous transfemoral aortic CoreValve $(R)$ implantations in high risk patients: another Polish good experience. Kardiol Pol 2009; 67: 1162-5.

21. Kolh P, Windecker S, Alfonso F, et al. 2014 ESC/EACTS Guidelines on myocardial revascularization. The Task Force on Myocardial Revascularization of the European Society of Cardiology (ESC) and the European Association for Cardio-Thoracic Surgery (EACTS). Developed with the special contribution of the European Association of Percutaneous Cardiovascular Interventions (EAPCI). Eur J Cardio-Thoracic Surg 2014; 46: 517-92.

22. Kappetein AP, Head SJ, Généreux P, et al. Updated standardized endpoint definitions for transcatheter aortic valve implantation: The Valve Academic Research Consortium-2 consensus document. J Am Coll Cardiol 2012; 60: 1438-54.

23. Abdel-Wahab M, Zahn R, Horack M, et al. Transcatheter aortic valve implantation in patients with and without concomitant coronary artery disease: comparison of characteristics and early outcome in the German multicenter TAVI registry. Clin Res Cardiol 2012; 101: 973-81.

24. Huczek Z, Zbroński K, Grodecki K, et al. Concomitant coronary artery disease and its management in patients referred to transcatheter aortic valve implantation: Insights from the POL-TAVI Registry. Catheter Cardiovasc Interv 2018; 91: 115-23.

25. Zahn R, Gerckens U, Linke A, et al.; German Transcatheter Aortic Valve Interventions-Registry Investigators. Predictors of oneyear mortality after transcatheter aortic valve implantation for severe symptomatic aortic stenosis. Am J Cardiol 2013; 112: 272-9.

26. Duncan A, Ludman P, Banya W, et al. Long-term outcomes after transcatheter aortic valve replacement in high-risk patients with severe aortic stenosis: the U.K. Transcatheter Aortic Valve Implantation Registry. JACC Cardiovasc Interv 2015; 8: 645-53.

27. Kleczynski P, Dziewierz A, Bagienski M, et al. Impact of coronary artery disease burden on 12-month mortality of patients after transcatheter aortic valve implantation. J Interv Cardiol 2016; 29: 375-81.

28. Serruys PW, Morice MC, Kappetein AP, et al.; SYNTAX Investigators. Percutaneous coronary intervention versus coronary-artery bypass grafting for severe coronary artery disease. N Engl J Med 2009; 360: 961-72.

29. Mohr FW, Morice MC, Kappetein AP, et al. Coronary artery bypass graft surgery vs. percutaneous coronary intervention in patients with three-vessel disease and left main coronary disease: 5 -year follow-up of the randomised, clinical SYNTAX trial. Lancet 2013; 381: 629-38.

30. Rodes-Cabau J, Webb JG, Cheung A, et al. Long-term outcomes after transcatheter aortic valve implantation: insights on prognostic factors and valve durability from the Canadian multicenter experience. J Am Coll Cardiol 2012; 60: 1864-75.

31. Vahanian A, Alfieri O, Andreotti F, et al. Guidelines on the management of valvular heart disease (version 2012). The Joint Task Force on the Management of Valvular Heart Disease of the European Society of Cardiology (ESC) and the European Association for Cardio-Thoracic Surgery (EACTS). Eur Heart J 2012; 33: 2451-96.

32. Beach JM, Mihaljevic T, Svensson LG, et al. Coronary artery disease and outcomes of aortic valve replacement for severe aortic stenosis. J Am Coll Cardiol 2013; 61: 837-48. 